\section{Haematology (36220)}

\section{SELF-ASSESSMENT QUESTIONNAIRE}

\section{SAQs and answers are ONLINE for RCP Fellows and Collegiate Members}

The SAQs printed in the CME section can only be answered online to achieve external CPD credits. The closing date is 21 January 2008 (midnight GMT).

\section{Change in format}

As announced in the previous issues, SAQs will now follow a best of five format in line with the MRCP(UK) Part 1 exam. Candidates are asked to choose the best answer from five possible answers. The online system, passwords and pass mark will remain the same. There may be teething problems and we would be grateful if all comments/problems could be sent in via email only: clinicalmedicine@rcplondon.ac.uk

We recommend that answers are submitted early so that any problems can be resolved before the deadline.

\section{The answering process}

1 To access the questions, log on to the Fellows and Members area www.rcplondon.ac.uk/Members/SAQ Please contact the Information Centre if you have lost or forgotten your username or password: infocentre@rcplondon.ac.uk

2 Select: Self assessment

3 At the top of the SAQ page select the current CME question paper

4 Answer all 10 questions in any order, by selecting the best answer

5 Check your answers and change them if you wish to

6 Click on Submit for final marking.

NOTE - after submitting your answers NO changes are possible.

\section{The marking process}

- You must submit the answers before the closing date shown at the top of the screen

- Answers will be marked automatically on the date displayed for that paper

- You can find your marks on the CME page under My past CME papers.

\section{Registering your external CPD credits}

A pass mark of $80 \%$ allows you to claim two external CPD credits. Only the first seven distance-learning credits will be counted as external; the remainder can be claimed as personal credits. Credits can be recorded using the online diary system. All Clinical Medicine SAQs are listed under External Approved CPD.
1 A 58-year-old woman with chronic lymphocytic leukaemia (CLL) receiving fludarabine, cyclophosphamide and rituximab chemotherapy had a haemoglobin $(\mathrm{Hb})$ of $8.5 \mathrm{~g} / \mathrm{dl}$ and symptoms of anaemia. Haematinics and iron parameters were normal. Epoetin (Epo) therapy was started. After four weeks, her $\mathrm{Hb}$ was $8.8 \mathrm{~g} / \mathrm{dl}$ and her serum ferritin had fallen significantly to the low end of the normal range. Other iron parameters remained within the normal 'iron replete' range. What is the best next step to improve $\mathrm{Hb}$ ?

(a) Convert to a less myelosuppressive chemotherapy regimen

(b) Increase the Epo dose

(c) Intravenous iron supplementation

(d) Oral iron supplementation

(e) Stop Epo and give a blood transfusion

2 A 62-year-old man with Philadelphia (Ph)-positive chronic myeloid leukaemia (CML) attended the clinic for review. He had been taking imatinib 400 mg daily for two years; after 12 months of therapy he had achieved a complete cytogenetic remission (CCR). However, recent repeat real-time quantitativepolymerase chain reaction ( $R Q-P C R)$ studies on peripheral blood and repeat bone marrow examination had shown a 2-log rise in $B C R-A B L$ transcript numbers and $60 \% \mathrm{Ph}$-positive cells on cytogenetic analysis, respectively. What is the most appropriate treatment at this stage?

(a) Allogeneic stem cell transplantation

(b) Continue imatinib and start interferon (IFN) alpha

(c) Stop imatinib

(d) Stop imatinib and start dasatinib

(e) Stop imatinib and start IFN alpha

3 A 43-year-old woman with $\mathrm{Ph}$-positive CML had been treated with imatinib $400 \mathrm{mg}$ daily for 12 months. She underwent repeat bone marrow examination which showed a CCR. What is the most appropriate further monitoring schedule?

(a) Weekly full blood counts

(b) Monthly bone marrow aspirates with cytogenetic examination

(c) Three-monthly bone marrow aspirates with cytogenetic examination 
(d) Three-monthly quantitation of $B C R-A B L$ transcript numbers in the peripheral blood by $R Q$ PCR

(e) Three-monthly screening for abl kinase mutations

4 A 10-year-old Sicilian boy was brought by his parents to the accident and emergency (A\&E) department with fevers and abdominal pain. His parents had noticed that his sclerae had become yellow. He had recently moved to the UK. He had been to a Mexican party with his family on the previous evening. He had no significant past medical history other than prolonged neonatal jaundice requiring phototherapy and was on no regular medication. His urine was noted to be dark and urinalysis was strongly positive for blood, but no red cells were seen on microscopy. Investigations showed $\mathrm{Hb} 6.2$ $\mathrm{g} / \mathrm{dl}$, white cell count $5.2 \times 10^{9} / \mathrm{l}$, platelet count $246 \times 10^{9} /$, reticulocyte count $370 \times 10^{9} / \mathrm{I}$, serum urea $7.7 \mathrm{mmol} / \mathrm{l}$, serum creatinine $125 \mu \mathrm{mol} / \mathrm{l}$, serum bilirubin $55 \mu \mathrm{mol} / \mathrm{l}$, alanine aminotransferase $18 \mathrm{iu} / \mathrm{l}$, aspartate aminotransferase $57 \mathrm{iu} / \mathrm{I}$ and lactate dehydrogenase $873 \mathrm{iu} / \mathrm{l}$. What is the most likely underlying diagnosis?
(a) Glucose-6-phosphate dehydrogenase deficiency
(b) Hereditary spherocytosis
(c) Phosphofructokinase deficiency
(d) Sickle cell anaemia
(e) Thalassaemia major

5 A five-year-old girl presented with a two-week history of breathlessness. Her parents had originally thought her symptoms were due to anxiety about starting school. She had previously been well other than intermittent jaundice which had become more marked recently. Her family originated from northern Sweden, although she had been born in the UK. Her father had undergone a splenectomy at the age of seven years but he did not know why. Her paternal grandmother had also had a splenectomy. On examination, there was a prominent firmness in the left upper quadrant of the abdomen. Investigations showed anaemia and increased osmotic fragility of her red cells. What abnormality is most likely to be seen on her blood film?
(a) Elliptocytes
(b) Ghost cells
(c) Prickle cells
(d) Spherocytes
(e) Stomatocytes

6 An 18-year-old African-Caribbean man presented to the A\&E department with shortness of breath and a cough productive of yellow sputum. On examination, his temperature was $38.0^{\circ} \mathrm{C}$ and his jugular venous pressure was elevated. Heart sounds were normal but there was a moderately loud ejection systolic murmur. There were coarse crackles at the right lung base. Chest X-ray revealed consolidation at the right base and prominent pulmonary vasculature. An echocardiogram showed evidence of pulmonary hypertension. What abnormality is most likely to have contributed to his pulmonary hypertension?
(a) High alveolar carbon dioxide concentrations
(b) Increased levels of free plasma $\mathrm{Hb}$
(c) Low arterial oxygen levels
(d) Low red cell adenosine triphosphate levels
(e) Low red cell 2,3-diphosphoglycerate levels

7 A 55-year-old Caucasian man presented with a 10-month history of fatigue. He was found to have generalised lymphadenopathy and $2 \mathrm{~cm}$ splenomegaly. Investigations revealed $\mathrm{Hb} 10.6 \mathrm{~g} / \mathrm{dl}$ (normal range 13-18), white cell count $25.0 \times 10^{9} / \mathrm{I}(4-11)$, neutrophils $4.0 \times 10^{9} / /(1.5-7)$, lymphocytes $20.5 \times 10^{9} / 1(1.5-4)$ and platelet count $100 \times 10^{9} / \mathrm{l}(150-400)$. A blood film showed numerous small mature lymphocytes with smear cells. What is the most appropriate next investigation in order to distinguish between CLL and mantle cell lymphoma?
(a) Bone marrow aspirate and trephine biopsy
(b) Excision biopsy of a lymph node
(c) Fine-needle aspiration cytology of a lymph node
(d) Immunophenotyping of a peripheral blood sample
(e) Virological screening including Epstein-Barr virus and HIV serology

8 An eight-year-old boy was referred for assessment following excessive bleeding at the time of tonsillectomy. He had bruised easily as an infant and there had been a suspicion of nonaccidental injury. He also reported occasional nose bleeds lasting up to $40 \mathrm{~min}$. Investigations revealed Hb $13.5 \mathrm{~g} / \mathrm{dl}$, platelet count 197 $\times 10^{9} /$, prothrombin time normal, activated partial thromboplastin time (APTT) normal, von Willebrand factor (vWF) antigen 29 iu/dl, vWF activity (by ristocetin cofactor assay ( $\mathrm{RCo})$ ) $<10 \mathrm{iu} / \mathrm{dl}$ and factor VIII (FVIII):C 53 iu/dl. Ristocetininduced platelet aggregation showed reduction in aggregation to $1.5 \mathrm{mg} / \mathrm{ml}$ and $1.2 \mathrm{mg} / \mathrm{ml}$, with absent aggregation at $0.75 \mathrm{mg} / \mathrm{ml}$. vWF factor multimers showed loss of high and intermediate molecular weight forms. Which type of von Willebrand disease (vWD) is he most likely to have?
(a) Type 1
(b) Type $2 \mathrm{~A}$
(c) Type $2 \mathrm{~B}$
(d) Type $2 \mathrm{M}$
(e) Type 3

9 A 17-year-old Caucasian girl was referred for assessment after prolonged bleeding following a wisdom tooth extraction. She had always tended to bruise easily 
and had experienced frequent prolonged nose bleeds during childhood. Her menstrual bleeding had been heavy since her menarche at the age of 13 . Investigations showed

$\mathrm{Hb} 2.3 \mathrm{~g} / \mathrm{dl}$, platelet count $246 \times$ $10^{9} / \mathrm{l}$, prothrombin time normal, APTT normal, vWF antigen 42 iu/dl, vWF activity (by RCo) $<10 \mathrm{iu} / \mathrm{dl}$ and FVIII:C $67 \mathrm{iu} / \mathrm{dl}$. Ristocetin-induced platelet aggregation showed marked reduction in aggregation to 1.5 $\mathrm{mg} / \mathrm{ml}$, with absent aggregation at $0.75 \mathrm{mg} / \mathrm{ml}$. All molecular forms of vWF multimers were present. Which type of vWD is she most likely to have?
(a) Type 1
(b) Type 2B
(c) Type $2 \mathrm{M}$
(d) Type $2 \mathrm{~N}$
(e) Type 3

10 A 78-year-old man with type 1 vWD required transurethral resection of his prostate. What is the most appropriate haemostatic treatment?
(a) Cryoprecipitate
(b) Desmopressin
(c) FVIII concentrate containing vWF
(d) Fresh frozen plasma
(e) Recombinant vWF concentrate

\section{CME Geriatric medicine SAQs}

Answers to the CME SAQs published in Clinical Medicine October 2007

$\begin{array}{lllll}\text { Q1 } & \text { Q2 } & \text { Q3 } & \text { Q4 } & \text { Q5 } \\ \text { (e) } & \text { (a) } & \text { (a) } & \text { (c) } & \text { (a) } \\ \text { Q6 } & \text { Q7 } & \text { Q8 } & \text { Q9 } & \text { Q10 } \\ \text { (b) } & \text { (d) } & \text { (b) } & \text { (c) } & \text { (b) }\end{array}$

